\title{
Value Creation through Urban Data Platforms: A Conceptual Framework
}

\author{
Samaneh Bagheri \\ Rotterdam School of \\ Management, \\ Erasmus University \\ Rotterdam \\ bagheri@rsm.nl
}

\author{
Tobias Brandt \\ Rotterdam School of \\ Management, \\ Erasmus University \\ Rotterdam \\ brandt@rsm.nl
}

\author{
Haydee Sheombar \\ Erasmus Centre for \\ Future Energy Business, \\ Erasmus University \\ Rotterdam \\ Sheombar@rsm.nl
}

\author{
Marcel van Oosterhout \\ Erasmus Centre for Data \\ Analytics, \\ Erasmus University \\ Rotterdam \\ moosterhout@rsm.nl
}

\begin{abstract}
In the context of smart cities, data-driven innovation and digital transformation have received increasing attention from practitioners and academics. The data-centric nature of smart city transformations highlights the essential role of urban data platform (UDP) to manage large and heterogeneous urban data sets and to facilitate interaction among data providers and users in a city ecosystem. To realize value creation through UDP, a comprehensive understanding of the key UDP dimensions and how they influence UDP adoption, use, and value creation are required. For this purpose, we first identify key UDP dimensions through a literature review. Second, by exploring and discussing their relationships with an expert panel, we develop a framework for understanding value creation through UDPs.

By identifying key dimensions of UDP and their effects on value creation through UDP, the proposed framework provides a systematic and comprehensive approach for understanding UDP adoption, use, and value creation. Thereby, this study helps city policymakers and business developers in realizing value from UDPs in city ecosystems.
\end{abstract}

\section{Introduction}

With the growth of urban population and rapid urbanization, cities face increasing challenges related to the sustainable operation and delivery of valueadding city services. By facilitating data-driven innovative city services, digital technologies can support cities in meeting these challenges and achieving sustainable prosperity [1]. Also, developing and offering data-driven innovative city services such as on-demand transport and intelligent water management increasingly requires multiple stakeholders from the private and public sectors, as well as citizens and academia, to collaborate and share data. To facilitate interaction among city stakeholders, to manage large and heterogeneous urban data sets, and to obtain valuable insights from such data an Urban data Platform (UDP) is required $[2,3]$.

UDPs are a subset of multi-sided digital platforms (e.g., Amazon marketplace, Airbnb) for secure and trusted data exchange between different user groups such as citizens, city governments, and businesses [3, 4]. The European Innovation Partnership on Smart Cities and Communities (EIP - SCC) [5] defines UDPs as using digital technologies to combine and enable data flows within and across city systems. The UDP adds further value by nurturing the cities' ecosystem towards making their (open) data (re)sources accessible to others. The city stakeholders may supply and sell data through the platform or build new business models on top of the platform. Thus, the UDP is considered to be an essential infrastructure in supporting data-driven innovative services and the delivery of smart city initiatives toward a smart, sustainable, and resilient city [2, 3].

Despite the prominent benefits of UDPs in city ecosystems, there is a lack of research regarding how to systematically increase adoption and use of UDPs. To realize value creation through UDPs, a comprehensive understanding of key UDP dimensions and their influence on UDP adoption, use, and value creation are required. In this context, key dimensions refer to the decision variables that are strategically important for the success of a UDP. Naturally, the identification of these key dimensions of data platforms in urban settings can benefit from prior studies on digital platforms in business contexts [4, 6-8]. However, to incorporate the idiosyncrasies of the smart city context, a more comprehensive view is needed. For this purpose, relevant information from the smart city literature can be used as several studies have identified different dimensions 
determining the success of smart city projects [9-12]. However, these studies usually focus on a particular aspect of the smart city transformation, and the dimensions they identify differ as a result. Therefore, they produce a fragmented picture of the complexity of smart city transformations and make an integrated, holistic view that covers all aspects necessary.

With respect to the relationship between the key dimensions and platform adoption, previous studies provide us a good understanding of the effect of generic adoption factors on technology adoption, such as trust [13-15], and organizational factors [16, 17]. However, less is known about the specific relationship between key dimensions of platforms and platform adoption, use, and value creation [18, 19].

The objective of this paper is, thus, to develop an integrative framework of the key UDP dimensions and the relationships between these dimensions and UDP adoption, use, and value creation. Specifically, the paper addresses the following research question: What are the key UDP dimensions, and how do they relate to the adoption and use of UDPs as well as value creation through those platforms?

We approach this question by, first, identifying the key dimensions of UDPs through a literature review. The resulting dimensions and their relationships are then explored and discussed with an expert panel consisting of city stakeholders from European cities who are currently involved in UDP projects. From these discussions, a framework for understanding value creation through UDPs is derived. The proposed framework provides a systematic and comprehensive approach for understanding UDP adoption, use, and value creation by identifying key dimensions of UDPs and describing their effects on value creation.

The outline of the paper is as follows. Section 2 describes the research methodology. The identified key dimensions of UDPs are described in Section 3. The framework of the UDP dimensions and their effect on UDP value creation is developed in Section 4. Finally, Discussion and Conclusion are presented in Section 5.

\section{Research Methodology}

In this study, we develop an integrative framework of key UDP dimensions and their relationships that determine the success of UDP adoption, use, and value creation in the context of a city ecosystem. The development of the framework comprises two steps. First, a literature review approach was applied to identify the key UDP dimensions from existing literature on digital platforms and smart cities. As UDPs have emerged from the confluence of these two phenomena digital platforms and smart city [3] - these strands of literature provide a foundation for the identification of the dimensions. This follows on the one hand from UDPs being regarded as a specific type of digital platforms and key dimensions that determine the success of digital platforms are likely to also be relevant to a UDP. On the other hand, UDPs are part of smart city initiatives, representing the keystone that connects the digital technologies infused into city systems to handle growing urbanization and keep cities livable and thriving. Accordingly, the key dimensions of a smart city are also likely to be relevant to the success of a UDP. Two separate literature reviews were conducted to identify dimensions of digital platforms and smart cities, respectively. The following search queries were used:

- ((“data platforms”) OR ("digital platforms”) OR ("platform ecosystem")) AND ((“dimension”) OR ("design”) OR ("driving factors") OR ("framework")) for the first review;

- ("smart city”) AND ((“dimension”) $O R$ ("design") OR ("driving factors") $O R$ ("framework")) for the second review.

We conducted a keyword-based search through the Science Direct, Springer, Emerald, and Wiley databases. In addition to examining the databases, we used a snowball sampling method to identify relevant articles that were referred to in the identified articles. The two literature searches resulted in a collection of key dimensions of digital platforms and smart city initiatives, as well as their underlying elements. From this collection, we identify those dimensions in which the platform and smart city contexts intersect, resulting in a list of the key dimensions of UDPs and their underlying elements (see Section 3). Specifically, we start from a set of dimensions required for the success of digital platforms and expands them to include the complementary dimensions essential for the success of smart city initiatives.

In the second step, we conducted an expert panel to obtain deeper insights into the relationships between these key dimensions of UPDs and the value creation mechanisms of the UDP (see Section 4). The panel was conducted in the period between February 1, 2020, and April 9, 2020, and it consisted of a balanced sample of 30 experts from European cities that are involved in a smart city project that is part of the EU Horizon 2020 initiative. To reflect the perspectives of the different stakeholders, this panel consisted of 12 experts from government institutions, 
12 experts from private companies, and six experts from academia or NGOs. The experts were asked to respond independently to a questionnaire. The following six open questions used to initiate a discussion on the experts' experiences and insights concerning the key UDP dimensions.

1. What should be the purpose of an Urban Data Platform?

2. Who should be the owner and manager of an Urban Data Platform?

3. What kind of value should be created with Urban Data Platforms?

4. Why should Urban Data Platforms be interoperable?

5. Why is citizen engagement needed for Urban Data Platforms?

6. How can trust be fostered and who needs to be trusted?

Based on the panel expert responses to these questions, a framework for value creation through UDP was derived (see Section 4).

\section{Key dimensions of urban data platform}

In this section, we, first, present the results of the literature review on digital platforms and smart cities concerning their dimensions and driving factors. Then, the key UDP dimensions and their underlying elements are described.

Concerning the literature review on digital platforms, prior studies underscore several dimensions of digital platforms [8, 20-22]. However, they often focus on a specific component of digital platforms. For instance, platform governance has been examined by a multitude of authors [23-25]. Another key dimension that has received considerable attention is the platform business model. While being studied in prior works, these dimensions have mostly been examined in isolation and a holistic approach is scarce yet. Regarding driving factors of digital platforms, Nikayin, et al. [26] suggest that factors such as technical and organizational openness, heterogeneity of interests, independency in the ecosystem, leadership, and selective incentives influence collective action for joint platform development. Engert, et al. [19] identify other factors that influence the adoption and growth of multi-sided platforms. In summary, prior works provide a fragmented view of what determines the success of a digital platform and lack particularly a focus on platform adoption [6, 19]. A more comprehensive view is thus needed.

From the literature review on smart cities, several studies with varying degrees of depth and coverage have emerged that underscore different dimensions of the smart city $[1,10,11]$. However, the results of these studies present are quite mixed. In some studies, smart city dimensions are introduced at a high abstraction level. For example, Chourabi, et al. [10] identify eight key dimensions of a smart city: management and organization, technology, governance, policy context, people and communities, economy, built infrastructure, and natural environment. In contrast, other studies focus on a specific dimension of a smart city, such as governance [12, 27], business model [28], and technical architecture [29], and provide a more detailed perspective on this dimension. Although such studies provide useful insights, they assemble to a fragmented picture of the smart city dimensions. An integrated view that covers all dimensions is thus required. Regarding the driving factors of smart cities, Ojo, et al. [30] suggest factors such as political leadership, adoption of integrated, holistic government approaches, and stakeholder collaboration and partnerships. However, a comprehensive understanding of how the multidimensional nature of the drivers of smart cities are linked to desired outcomes is still lacking [31].

From the two reviews, we compiled a collection of key dimensions related to UDP in Table 1. Each of the dimensions encompasses several underlying elements described in the remainder of this section.

Table 1. Key dimensions of urban data platforms

\begin{tabular}{|c|c|}
\hline \multicolumn{2}{|c|}{ Platform purpose } \\
\hline City services & $\begin{array}{l}\text { Environmental } \\
\text { sustainability }\end{array}$ \\
\hline Social impact & Economic development \\
\hline \multicolumn{2}{|c|}{ Platform governance } \\
\hline Principles & Institutional arrangement \\
\hline Data governance & Revenue Model \\
\hline \multicolumn{2}{|l|}{ Control } \\
\hline \multicolumn{2}{|c|}{ Platform technical design } \\
\hline Privacy & Security \\
\hline Data analytics capability & $\begin{array}{c}\text { Business model support } \\
\text { tools }\end{array}$ \\
\hline \multicolumn{2}{|c|}{ Platform manager capabilities } \\
\hline Leadership & $\begin{array}{c}\text { Cross-organizational } \\
\text { collaboration }\end{array}$ \\
\hline Ecosystem nurturing & Data quality management \\
\hline \multicolumn{2}{|c|}{$\begin{array}{c}\text { Engaging stakeholders } \\
\text { Quadruple helix Collaboration }\end{array}$} \\
\hline
\end{tabular}

Platform purpose is an indicator of the breadth and depth of the vision behind a UDP in a city. Without a clear vision and purpose, user groups will 
be reluctant to join a platform [32]. Given that the ultimate objectives of smart city initiatives are city services improvement, economic development, environmental sustainability, and social progress of a city [10,11,33], the UDP purpose is to contribute to fulfilling the city's vision and strategy along these lines.

Platform governance defines who makes what decisions about a platform (ecosystem) [21]. Appropriate governance arrangements that allow data sharing, support decision-making, and facilitate interaction among ecosystem stakeholders are key to the success of platform ecosystems as a whole [25]. Governance of UDP in the context of city ecosystems can be achieved through the development and implementation of institutional arrangements, principles, data governance, revenue model, and control.

The institutional arrangement represents one of the main components of platform governance. It consists of a governance structure, funding, and a development strategy. Governance structure refers to decision rights (i.e., decision-making authority and responsibility), the ownership status of a platform amongst the ecosystem participants, and rules and procedures that need to be followed to make decisions [21, 25, 34]. There are three possible forms of platform governance structure: central governance where decisions are taken by a single organization that usually leads a platform; some form of collaborative decision-making and shared ownership (e.g., public-private ownership); and a decentral governance model $[4,21]$.

The second element of the institutional arrangement is the funding of the platform. The availability of public funding and private financing resources as well as the return on investments for organizations investing in UDPs are crucial for the success of a UDP in a city ecosystem [9, 35, 36]. A UDP is expected to create and contribute to economic, environmental, and social value- often referred to as the triple bottom line [37] - in a city ecosystem. Accordingly, the returns of investments of UDP projects are not always captured in monetary value and can be broadened to social value creation (nonmonetary benefits)[36].

The last element of institutional arrangement is the development strategy of a platform. In line with the smart city development policy, the development of a UDP can be targeted at different levels: local, regional, national, and international [33].

As argued by Tan et al., platform governance is based on three principles of openness, interoperability, and transparency [38]. Platform
Openness as a governance-related concept refers to reducing restrictions about who can participate on the platform and naturally contributes to platform adoption and potential network effects [32]. Furthermore, the degree to which a platform is open or closed is one of the primary drivers for the growth and sustainability of the platform [19, 26].

Interoperability refers to the ability of different systems to interact and share information [35]. Lack of interoperability might lead to incompatible data exchange formats and protocols, which may in turn reduce the economies of scale of value-adding services using shared data of the platform [22]. UDPs should facilitate interoperability among a wide range of city systems to automatically share data and combine services. Interoperable urban data platforms that promote open standards, APIs, and shared data models are crucial for removing barriers such as noninteroperable proprietary protocols. A higher degree of interoperability also makes the UDP more appealing for new partners to join. Furthermore, UDP interoperability also facilitates data sharing between cities.

The third principle of platform governance is transparency. It refers to the understanding of what is happening (e.g., transparency about the rules of engagement, the use of data, the analytics and algorithms on the platform), and why it is happening, thus determining whether platform-related governance decisions are easy to follow and understandable [25].

Within a platform ecosystem, data governance refers to defining, applying and monitoring the patterns of rules and authorities for directing the proper functioning of, and ensuring the accountability for, the entire data lifecycle (creating, processing and sharing, using) [39]. For data governance, it should be clearly defined which roles are relevant for the provisioning and processing of data, and how these roles are allocated to the data decision domains such as data principles, data quality [40]. The goals of data governance are ensuring the quality and proper use of data and helping utilize data to create public value [39]. Data platforms should address basic questions of data governance such as quality of original data; data ownership and access [4, 41].

The revenue model - as a governance mechanism within platform ecosystems - describes how the platform generates income and earns money through the provision of its service [25]. The revenue model for data platforms can be a payment by data providers or users in the form of, for instance, subscription (data is made available for a certain period of use), commission (for each data transaction), and advertising [42]. Furthermore, the revenues of a 
platform depend on the price associated with the service. As data platforms often focus on getting the various stakeholder groups on board, a viable pricing policy is to subsidize one side in order to attract the other side to join the platform [22, 25, 32], e.g., by lowering prices or offering access for a fee. It is expected that the establishment of the right pricing structure by the platform manager influences the adoption decisions of platform users and supports network effects within a platform ecosystem [19, 22].

The control dimension of platform governance refers to how the platform managers coordinate the platform ecosystem and manage relationships with stakeholders to encourage their desirable behavior [21]. For doing this, the platform manager implements two types of control mechanisms: formal control (gatekeeping and process control) and informal control (e.g., shared norms and values) over the city stakeholders involved in the provisioning and utilization of urban data.

Gatekeeping or input control refers to the degree to which the platform manager uses selection criteria on which stakeholders are allowed to enter into the platform's ecosystem and uses pre-defined criteria to determine which data is allowed on the platform [21].

Process control refers to methods, rules, and procedures that are in place to regulate the platform and to observe and monitor the desirable behavior of the stakeholders of a platform ecosystem [7, 21].

Informal control refers to the degree to which the platform manager relies on norms and values that it shares with all stakeholders involved in a platform ecosystem [21]. A similar set of values, beliefs, and shared norms provides a common foundation for the stakeholders within a city ecosystem. It can promote their commitments to the objectives of the UDP and encourage desirable behaviors.

Platform technical design dimension deals with platform architecture which aims to ensure technical capabilities of the platform in terms of privacy, security, data analytics, and business model support tools. Privacy and security-related issues should be addressed by the architectural design of a platform for trusted and secure data exchange within a platform ecosystem [20]. Data owners and users require that sensitive data is protected when they interact through urban data platforms. Thus, security and privacy protection should be considered during capturing, processing, aggregating, storing, and sharing data through the UDP in the city ecosystem [29]. From a technical perspective, platform design is based on a layered modular architecture with interfaces between layers [21]. In this regard, setting rules and standards on how to interface between the various layers of the platform that enable secure data exchange is a critical success factor [43].

Besides security and privacy concerns that should be met by the technical design, the UDP should have data analytics capabilities as it aims to improve city operations and services [3]. Such technical capabilities range from accessing data towards semantification, aggregation, and advanced analytics to analyze and gain useful insights from multiple urban datasets.

From a technical perspective, a platform should also provide business model support tools to enhance the economies of scope by encouraging new communities (e.g., data-driven start-ups, developers, and established firms) to join the platform ecosystem in order to explore new business opportunities, or to enhance their existing business models [44]. Typical technical support tools are Application Programming Interfaces (APIs) and Software Developers Kits (SDKs). Such technical tools allow access and interaction with the platform and mediate between the platform and its users. Hence, they play an important role in opening up new business opportunities within a platform ecosystem [21, 25, 44].

Platform manager capabilities refer to the extent to which the platform managers have the abilities and skills required for management and orchestration of a platform ecosystem that creates value for all stakeholders. These capabilities are defined in terms of four constructs: ecosystem nurturing, cross-organizational collaboration, leadership, and data quality management. We make a distinction between the platform owner and the platform manager. The platform owner is responsible for the underlying platform technology upon which the ecosystem operates and has the intellectual property and legal control over the platform technology. In contrast, the platform manager maintains, runs, and develops the platform within the guidelines provided by the platform owner.

Ecosystem nurturing capability is the ability of the platform managers to nurture adoption and use of the platform as well as on-going collective innovation and exploration of new business models for the growth of the platform ecosystem [44].

Cross-organizational collaboration capability is the ability of the platform managers to collaborate with ecosystem stakeholders without having formal authority over these stakeholders [24]. 


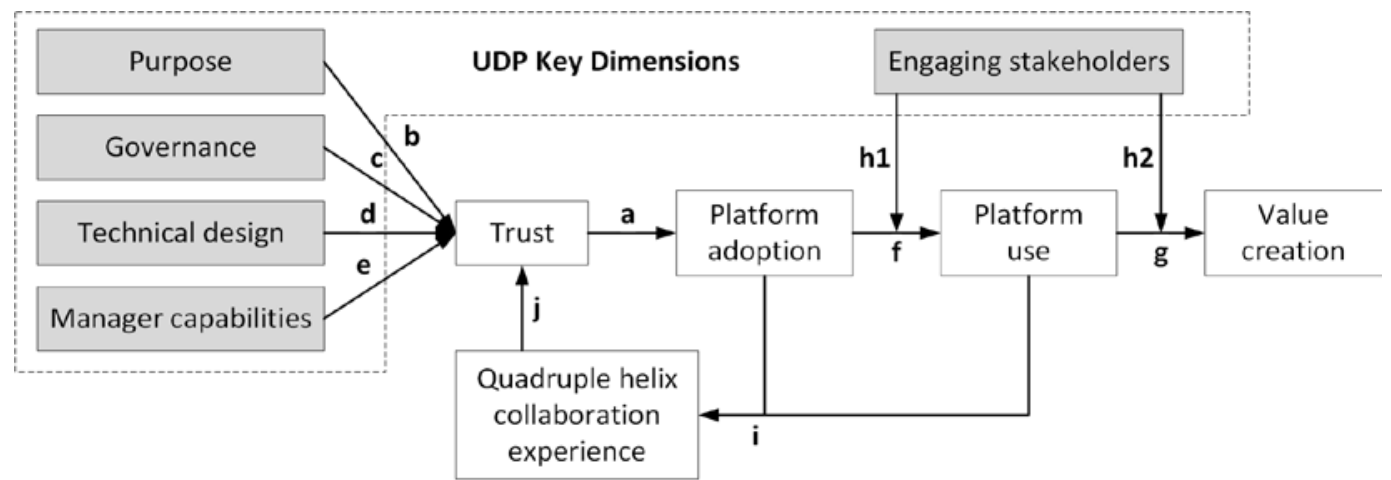

Figure 1. A framework for value creation in Urban Data Platform ecosystems

Leadership capability is the ability of the platform managers to support and coordinate collective action in a platform ecosystem, manage conflicts, and create incentives for ecosystem members to provide input and to collaborate [26, 33].

Data quality management capability is the ability of the platform managers to communicate and handle data-related issues with the relevant stakeholders to ensure data quality within the platform ecosystem. Data quality is a multifaceted construct, encompassing a set of quality attributes, such as accuracy, timeliness, completeness, consistency, and relevance, which all determine whether data is fit for use [39]. Approaches for achieving this include, for instance, monitoring the data lifecycle of creating, processing, sharing, and using data to create value [45]. To do so, platform managers should possess relevant knowledge and reasonable multi-disciplinary skills from domains such as machine learning or data management as well as analytical/modeling skills and business domain knowledge [46].

Engaging stakeholders refers to the degree to which a UDP is designed to foster and enable collaboration, partnerships, and co-creation between different stakeholder groups. Engaging stakeholders is based on a quadruple helix collaboration model that includes government, companies, universities, and citizens. Quadruple helix collaborations further enhance technology diffusion and reduce technology resistance in cities by including citizens as cocreators and social innovators [1].

\section{A framework for value creation in UDP ecosystems}

Based on the key dimensions identified, the responses from the members of the expert panel provide further insights into how these dimensions can support value creation within a UDP ecosystem. The resulting framework for value creation through UDP is illustrated in Figure 1. It relates the key dimensions that were previously identified to the dynamics of platform adoptions and use, ultimately leading to value creation.

In principle, trust is the driving factor for UDP adoption and use and is influenced by platform purpose, governance, technical design, and platform manager capabilities. The impact of platform adoption on platform use is moderated by the degree to which the platform is designed to actively engage stakeholders, as this moderates the effect of the platform usage on value creation. Finally, the quadruple helix collaboration experience is described as a feedback loop between platform adoption, platform use, and trust. This experience is built over time, through adoption and use of the UDP and, in turn, strengthens trust. In the remainder of this section, we will reflect on these relationships and the expert feedback in more detail.

The panel experts argue that trust is the major determinant of UDP adoption (relationship a). They distinguish between three forms of trust - trust in the platform itself; trust in the organizations behind the platform, i.e. the platform manager, owner, and financer; and mutual trust between the public and private partners that are involved in the UDP ecosystem.

The organizational trust research field provides various starting points on how trust can be improved. Mayer, et al. [47] suggest three determinant factors that affect the trust one party has for another: benevolence, integrity, and capability. These three trust determinants have been well accepted within the research community on trust in technology and the relationship between the trust determinants and technology adoption has been supported in various studies $[15,17,48]$. Similarly, in this paper, we posit 
that benevolence, integrity, and capability are the drivers of trust within the UDP adoption process. We proceed by providing definitions of these constructs and discussing their role in the context of the framework illustrated in Figure 1.

Benevolence is the extent to which a trustee (e.g., person, technological artifact, or institution) is believed to want to do good to the trustor [47]. It is related to the purpose of the UDP and, hence, the rationale of stakeholders to engage in a UDP. Thus, the platform purpose is one of the drivers of trust (relationship b). The panel experts state that the UDP ambition is one or a combination of the following four objectives: 1) to improve city services, policies, and decision making; 2) to foster economic innovation; 3) to create more sustainable and resilient cities, and 4) to foster social innovation. These objectives should be communicated to the city stakeholders for the platform to build up trust in the eyes of these stakeholders.

The second key driver of trust is integrity i.e., the degree to which a trustee adheres to a set of principles (e.g., honesty and fair treatment) [47]. In the organizational setting, clear and transparent governance frameworks in combination with norms concerning fairness and accountability are measures to ensure integrity. Trust in the platform derives mainly from good governance that ensures positive platform interaction and transaction experiences for stakeholders. Thus, platform governance is an important driver of trust (relationship c). In this regard, for instance, most panel members agree that the government should take the lead, predominantly for reasons related to data ethics. Regarding the institutional arrangement element of platform governance, the majority view of the expert panel was that UDP governance should be a public-private endeavor. There is consensus that the management of the UDP should be a joint collaborative effort. This view is supported by the fact that the capabilities needed to manage a UDP are distributed across the public and private sector organizations because they bring different capabilities to the table. As stated by the panelists, the public sector is most suited to control the setting of data privacy norms, determining data ownership rules, and determining platform access rules in such a set-up. Also, from the panelists' perspectives, the private sector would focus on innovating platform tools and services, generating and capturing in-platform data, and pricing of inplatform services. Such shared-responsibility arrangements thus provide further support for enhancing trust.

The third key driver of trust is capability, meaning that the trustee has the ability, skills, and expertise to perform effectively in a certain context or with a certain task [47]. In this study, we make a distinction between two types of capabilities. First, capabilities or functionalities that have been technically embedded in the platform itself and, second, the capabilities of the platform manager.

From the technical perspective, trust in platforms relies on the design and development of crucial capabilities, functions, and features of urban data platforms that allow them to perform tasks well for city stakeholders. Platform technical design that offer key technical capabilities of the platform- i.e., credible security and privacy protections, data analytic capability, and business model support tools- are deemed more reliable and trustworthy. Thus, Platform technical design will enhance the trust in the UDP (relationship d).

The capabilities of the platform manager are also considered by the panel members as an important driver of trust (relationship e). The panel experts propose that some of these key capabilities, e.g., setting the right rules and regulations for the UDP, are better entrusted to public sector organizations, whereas other capabilities, such as nurturing the ecosystem, come more naturally to the private sector. The experts also state that trust in government institutions by the private sector can be increased by improving the institutions' capabilities, i.e. the skills, competencies, and leadership characteristics in the domain of UDPs. They also suggest that trust in the private sector by the government institutions can be increased by improving the integrity of companies, i.e. the perception that companies have principles (e.g. accountability, inclusion, social responsibility) that are acceptable to the government.

The panel suggests that trust in the government by the private sector can be strengthened by creating collaborative experiences with the government, e.g. collaborating in pilots and proofs of concepts. They also state that trust in the private sector by the government can be increased by creating collaborative experiences with the private sector, in turn. The previous experience between the stakeholders involved in the UDP leads to a feeling of greater credibility between those involved stakeholders. This provides evidence that collaborative experience can serve as an important driver to improve mutual trust (relationship j). As a consequence, there is a feedback loop between trust, platform adoption, platform use, and the quadruple helix collaboration experience. The experience from collaboration within the quadruple helix of public and private sectors, citizens, and academia is built over time through adoption and use of the UDP 
(relationship i) and, in turn, reinforces the trust (relationship $\mathbf{j}$ ).

Furthermore, a platform design that actively seeks to engage stakeholders in value co-creation is perceived as moderating the success of UDP adoption and use (relationships h1 and h2). The panelists stated that stakeholders can provide valuable insights into the needs of the city by collaboration in collecting, creating, analyzing, and using urban data. More specifically, they emphasize the importance of a platform designed to engage citizens. While a crucial objective of many UDP initiatives, only a few cities have been able to successfully build up collaborations between citizens and other ecosystem stakeholders. From the point of view of the expert panel, the government needs to emphasize the use of the platform to support citizens by strengthening community, democracy, privacy, and data ownership. The private sector sees the relevance of engaging citizens in the design phase of the platform so that they build something the customer wants. Both sectors agree on enabling citizen entrepreneurship, for instance by helping them to monetize their data.

\section{Discussion and Conclusion}

Urban data platforms enable trusted data exchange between stakeholders in a city ecosystem and aim to promote sustainable solutions to urban challenges, foster societal engagement, and facilitate scaling up smart city solutions. The importance and relevance of data platforms are acknowledged both in the literature on smart cities [2, 3] and digital platforms [4, 6]. However, despite the contributions of previous studies on identifying key dimensions of digital platforms, they focus mainly on single dimensions and rarely consider platform adoption [19], which is a crucial challenge in the context of UDPs.

In this study, we have identified five key dimensions that determine the success of such platforms. We also contribute to the literature by providing evidence on how these key dimensions can support value creation through UDPs in the context of city ecosystems. The proposed framework provides a systematic and comprehensive approach for understanding the respective effects of the key UDP dimensions on UDP adoption, use, and value creation. It can thus support the decision-making process of platform managers and help city policymakers and business developers in realizing value from UDP in the city ecosystems.

We identify trust as a major factor that determines platform adoption, use, and value creation. This finding is in line with prior studies on technology adoption that emphasized trust as a major driver for the acceptance and use of new technology [13, 16, 17]. The leading role of trust is also highlighted in platform studies [4]. Yoffie, et al. [49] identify that lack of trust is one of the failure factors of platform businesses by studying 209 failed platforms. In contrast, mutual trust between platform stakeholders has been identified as a crucial factor in the success of platform ecosystems [25]. While previous studies mainly focused on general factors of organization, technology, and the environment $[13,14]$, we focus on the key decision variables of UDPs as the drivers of trust. The findings of this study suggest that key dimensions of a UDP - platform purpose, governance, platform technical design, and the platform manager capabilities - are required to build the trust needed for UDP to successfully create sustainable value. Thereby, we provide an in-depth understanding of value creation through UDPs.

Nevertheless, our investigation was limited to the European context. To improve the generalizability of the research results, the framework needs to be validated in other contexts in future studies. Secondly, we derived key dimensions of UDPs and discussed their influence on value creation through UDPs from supply-side perspectives. To provide a balanced view of UDP adoption, demand-side perspectives should also be included. Therefore, how users make decisions on adopting UDP should be investigated in future work. Thirdly, adoption and use of platforms follows evolutionary steps, reflected in a (feedback) learning loop within the framework. Since the early maturity stages of most existing urban data platforms limit the degree to which this addition can be validated, the evolutionary perspective and learning loop require further empirical investigation as part of a longitudinal study of UDP within a city ecosystem.

\section{Acknowledgements}

This research has been supported by the RUGGEDISED project funded by the European Union's Horizon 2020 research and innovation programme under grant agreement No 731198. The sole responsibility for the content of this document lies with the authors and does not necessarily reflect the opinion of the European Union. 


\section{References}

[1] M. Hämäläinen, "A Framework for a Smart City Design: Digital Transformation in the Helsinki Smart City," in Entrepreneurship and the Community, ed: Springer, 2020, pp. 63-86.

[2] S. Cuno, L. Bruns, N. Tcholtchev, P. Lämmel, and I. Schieferdecker, "Data Governance and Sovereignty in Urban Data Spaces Based on Standardized ICT Reference Architectures," Data, vol. 4, p. 16, 2019.

[3] S. Barns, "Smart cities and urban data platforms: Designing interfaces for smart governance," City, culture and society, vol. 12, pp. 5-12, 2018.

[4] B. Otto and M. Jarke, "Designing a multi-sided data platform: findings from the International Data Spaces case," Electronic Markets, vol. 29, pp. 561-580, 2019.

[5] "EIP-SCC Urban Platform Management Framework," European Innovation Partnership on Smart Cities and Communities (EIP-SCC)2016.

[6] M. de Reuver, C. Sørensen, and R. C. Basole, "The digital platform: a research agenda," Journal of Information Technology, vol. 33, pp. 124-135, 2018.

[7] S. Mukhopadhyay, M. de Reuver, and H. Bouwman, "Effectiveness of control mechanisms in mobile platform ecosystem," Telematics and Informatics, vol. 33, pp. 848-859, 2016.

[8] N. Tura, A. Kutvonen, and P. Ritala, "Platform design framework: conceptualisation and application," Technology Analysis \& Strategic Management, vol. 30, pp. 881-894, 2018.

[9] G. F. Camboim, P. A. Zawislak, and N. A. Pufal, "Driving elements to make cities smarter: Evidences from European projects," Technological Forecasting and Social Change, vol. 142, pp. 154-167, 2019.

[10] H. Chourabi, T. Nam, S. Walker, J. R. Gil-Garcia, S. Mellouli, K. Nahon, et al., "Understanding smart cities: An integrative framework," in 2012 45th Hawaii international conference on system sciences, 2012, pp. 2289-2297.

[11] J. H. Lee, M. G. Hancock, and M.-C. Hu, "Towards an effective framework for building smart cities: Lessons from Seoul and San Francisco," Technological Forecasting and Social Change, vol. 89, pp. 80-99, 2014.

[12] R. W. S. Ruhlandt, "The governance of smart cities: A systematic literature review," Cities, vol. 81, pp. 123, 2018.

[13] J. Lansing and A. Sunyaev, "Trust in Cloud Computing: conceptual typology and trust-building antecedents," ACM SIGMIS Database: the DATABASE for Advances in Information Systems, vol. 47, pp. 58-96, 2016.

[14] L. Alzahrani, W. Al-Karaghouli, and V. Weerakkody, "Analysing the critical factors influencing trust in e-government adoption from citizens' perspective: A systematic review and a conceptual framework," International business review, vol. 26, pp. 164-175, 2017.

[15] I. Benbasat and W. Wang, "Trust in and adoption of online recommendation agents," Journal of the association for information systems, vol. 6, p. 4, 2005.

[16] I. Sila, "Factors affecting the adoption of B2B ecommerce technologies," Electronic commerce research, vol. 13, pp. 199-236, 2013.

[17] A. K. Asare, T. G. Brashear-Alejandro, and J. Kang, "B2B technology adoption in customer driven supply chains," Journal of Business \& Industrial Marketing, 2016.

[18] F. De Prieëlle, M. De Reuver, and J. Rezaei, "The Role of Ecosystem Data Governance in Adoption of Data Platforms by Internet-of-Things Data Providers: Case of Dutch Horticulture Industry," IEEE Transactions on Engineering Management, 2020.

[19] M. Engert, M. Pfaff, and H. Krcmar, "Adoption of Software Platforms: Reviewing Influencing Factors and Outlining Future Research," in Twenty-Third Pacific Asia Conference on Information Systems: PACIS, 2019.

[20] D. Fürstenau, C. Auschra, S. Klein, and M. Gersch, "A process perspective on platform design and management: evidence from a digital platform in health care," Electronic Markets, vol. 29, pp. 581596, 2019.

[21] A. Tiwana, Platform ecosystems: Aligning architecture, governance, and strategy: Newnes, 2013.

[22] M. de Reuver and W. Keijzer-Broers, "Trade-offs in designing ICT platforms for independent living services," in 2015 IEEE International Conference on Engineering, Technology and Innovation/International Technology Management Conference (ICE/ITMC), 2015, pp. 1-6.

[23] M. de Reuver and H. Bouwman, "Governance mechanisms for mobile service innovation in value networks," Journal of Business Research, vol. 65, pp. 347-354, 2012.

[24] S. Mukhopadhyay and H. Bouwman, "Orchestration and governance in digital platform ecosystems: a literature review and trends," Digital Policy, Regulation and Governance, 2019.

[25] M. Schreieck, A. Hein, M. Wiesche, and H. Krcmar, "The challenge of governing digital platform ecosystems," in Digital marketplaces unleashed, ed: Springer, 2018, pp. 527-538.

[26] F. Nikayin, M. De Reuver, and T. Itälä, "Collective action for a common service platform for independent living services," International journal of medical informatics, vol. 82, pp. 922-939, 2013.

[27] W. Castelnovo, G. Misuraca, and A. Savoldelli, "Smart cities governance: The need for a holistic approach to assessing urban participatory policy making," Social Science Computer Review, vol. 34, pp. 724-739, 2016.

[28] N. Walravens and P. Ballon, "Platform business models for smart cities: from control and value to governance and public value," IEEE Communications Magazine, vol. 51, pp. 72-79, 2013.

[29] E. F. Z. Santana, A. P. Chaves, M. A. Gerosa, F. Kon, and D. S. Milojicic, "Software platforms for smart cities: Concepts, requirements, challenges, and 
a unified reference architecture," ACM Computing Surveys (Csur), vol. 50, pp. 1-37, 2017.

[30] A. Ojo, E. Curry, T. Janowski, and Z. Dzhusupova, "Designing next generation smart city initiatives: The SCID framework," in Transforming city governments for successful smart cities, ed: Springer, 2015, pp. 43-67.

[31] T. Yigitcanlar, M. Kamruzzaman, L. Buys, G. Ioppolo, J. Sabatini-Marques, E. M. da Costa, et al., "Understanding 'smart cities': Intertwining development drivers with desired outcomes in a multidimensional framework," Cities, vol. 81, pp. 145-160, 2018.

[32] M. de Reuver, B. Nederstigt, and M. Janssen, "Launch strategies for multi-sided data analytics platforms," 2018.

[33] T. Nam and T. A. Pardo, "Smart city as urban innovation: Focusing on management, policy, and context," in Proceedings of the 5th international conference on theory and practice of electronic governance, 2011, pp. 185-194.

[34] P. Constantinides, O. Henfridsson, and G. G. Parker, "Introduction-platforms and infrastructures in the digital age," ed: INFORMS, 2018.

[35] P. Pierce and B. Andersson, "Challenges with smart cities initiatives-A municipal decision makers' perspective," 2017.

[36] P. Giourka, M. W. Sanders, K. Angelakoglou, D. Pramangioulis, N. Nikolopoulos, D. Rakopoulos, et al., "The Smart City Business Model Canvas-A Smart City Business Modeling Framework and Practical Tool," Energies, vol. 12, p. 4798, 2019.

[37] A. Joyce and R. L. Paquin, "The triple layered business model canvas: A tool to design more sustainable business models," Journal of cleaner production, vol. 135, pp. 1474-1486, 2016.

[38] F. T. C. Tan, S. L. Pan, and M. Zuo, "Realising platform operational agility through information technology-enabled capabilities: resource-interdependence perspective," Information Systems Journal, vol. 29, pp. 582-608, 2019.

[39] M. Janssen, P. Brous, E. Estevez, L. S. Barbosa, and T. Janowski, "Data governance: Organizing data for trustworthy Artificial Intelligence," Government Information Quarterly, p. 101493, 2020.

[40] V. Khatri and C. V. Brown, "Designing data governance," Communications of the ACM, vol. 53, pp. 148-152, 2010.

[41] T. Nokkala, H. Salmela, and J. Toivonen, "Data Governance in Digital Platforms," in AMCIS, 2019.

[42] R. Schüritz, S. Seebacher, and R. Dorner, "Capturing value from data: Revenue models for data-driven services," in Proceedings of the 50th Hawaii International Conference on System Sciences, 2017.

[43] F. Saadatmand, R. Lindgren, and U. Schultze, "Configurations of platform organizations: Implications for complementor engagement," Research Policy, vol. 48, p. 103770, 2019.

[44] T. Isckia, M. De Reuver, and D. Lescop, "Orchestrating platform ecosystems: the interplay of innovation and business development subsystems,"
Journal of Innovation Economics Management, pp. 197-223, 2020.

[45] B. Otto, K. Wende, A. Schmidt, and P. Osl, "Towards a framework for corporate data quality management," 2007.

[46] K. D. A. Carillo, "Let's stop trying to be "sexy"preparing managers for the (big) data-driven business era," Business Process Management Journal, 2017.

[47] R. C. Mayer, J. H. Davis, and F. D. Schoorman, "An integrative model of organizational trust," Academy of management review, vol. 20, pp. 709-734, 1995.

[48] A. Alsaad, R. Mohamad, and N. A. Ismail, "The moderating role of trust in business to business electronic commerce (B2B EC) adoption," Computers in Human Behavior, vol. 68, pp. 157-169, 2017.

[49] D. B. Yoffie, A. Gawer, and M. A. Cusumano, "A study of more than 250 platforms a reveal why most fail," Harvard Business Review, 2019. 